\title{
Pragmatic Analysis of Fuzziness in Advertising English
}

\author{
Lei Chen \\ School of Foreign Languages, Henan University of Technology \\ Zhengzhou 450001, China \\ E-mail: asmallworld@126.com
}

Received: February 12, $2011 \quad$ Accepted: March 1, $2011 \quad$ doi:10.5539/ach.v3n2p29

\begin{abstract}
The article tentatively explores the fuzzy expressions in advertising English to realize the ultimate goal of advertising from the perspective of pragmatics. This study is devoted to the pragmatic theories employed by the advertisers in order to make advertisements persuasive, impressive to the target audience. Equipped with the pragmatic knowledge, the target audience can understand advertising language clearly.
\end{abstract}

Keywords: Fuzziness, Advertising English, Pragmatic principle

\section{Analysis of Advertising Language}

Nowadays, advertising has penetrated every corner our life pervasively. However, its language is the main carrier of advertising message. Advertising may take many forms, but language is of crucial importance. Advertising language is a style of immediate impact and rapid persuasiveness. In order to "attract attention, arouse interest, stimulate desire, create conviction and get action", it is necessary for the advertisers to catch the audience's attention. The language of advertising, among other aids, is of decisive importance to the persuasiveness and effectiveness of advertisements.

Fuzziness is frequently used in designing advertisements. Some scholars analyze fuzziness in advertising English from the angles of sociolinguistics, cross-cultural studies, stylistics, etc. The traditional discussion on fuzziness mainly concerns about the language features. However, it is found that few efforts has been put on the systematic analysis of the relationship between the fuzzy expressions in advertising English and the pragmatic principles.

\section{Analysis of Fuzziness}

The paper A Tentative Exploration of Fuzzy Language by Wu Tieping has inspired extensive study on fuzziness in China. There are several reasons for advertisers to employ fuzziness in advertising language. One of the reasons is the existence of various supervising organization, such as the Advertising Authority in Britain or the American Federal Trade Commission, which regulate what advertisers can say and how they should say. It is generally believed that the appropriate use of fuzzy expressions in advertising language may bring direct and indirect profits to the producers and advertisers. Under this circumstance, fuzziness is a useful help. As a new and borderline discipline, the study of fuzzy linguistics covers the following aspects (Wu and Chen, 2001, p.7):

1) Analysis of fuzziness within the various levels of natural language;

2) Exploration on the source of linguistic fuzziness and the factors that influence it;

3) Dialectic relations of fuzziness and precision;

4) Quantitative description of fuzzy language using fuzzy sets theory;

5) Studies on the relations between fuzzy linguistics and other linguistic theories, and how to apply the research results of the former to the latter;

6) Scientifically defining and distinguishing the basic concepts and special terms of fuzzy linguistics.

\section{Pragmatic Analysis of Fuzziness in Advertising English}

Advertising, as a special form of communication, is a dynamic process. Understanding advertising language is a process of decoding and needs context. Thus, the pragmatic approach might be the ideal approach to the analysis of advertising. The study is undertaken from the pragmatic perspective, which not only help to enrich the understanding of fuzziness but also help to promote the studies of advertising language and make the previous studies about advertising more practical. It also reveals that pragmatics does set a solid theoretical foundation for advertising studies. 


\subsection{Fuzziness and Politeness Principle}

As a special form of communication, the commercial advertisements are actually a kind of persuasive speech act, aiming to persuade the potential consumers to accept and buy the advertised products or services. In order to achieve this purpose, advertisers frequently employ some strategies in the advertising language. One of the effective ways to achieve this aim is by applying the Politeness Principle.

In everyday life, we have to communicate with each other to reach a variety of communicative goals. Grice's theory of Conversational Implicature is a useful guideline conducting people's behavior in conversation, but sometimes it also fails to explain some linguistic phenomena. According to Leech (1983, Ch.4), there is a politeness principle with the Cooperative Principle and the conversational maxims. He points out that the Cooperative Principle is insufficient in explaining "the relation between sense and force" in that it cannot explain " (i) why people are often so indirect in conveying what they mean; and (ii) what is the relation between sense and force when non-declarative types of sentence are being considered" (1983, pp.79-80). As a result, he proposes the Politeness Principle as rescuing the Cooperative Principle "in the sense that politeness can satisfactorily explain exceptions to and apparent deviations from the CP"(Thomas, 1995, p.158). The Politeness Principle runs as follows: "Minimize (other things being equal) the expression of impolite beliefs; maximize (other things being equal) the expression of polite beliefs"(Leech, 1966, p. 81). Therefore, the Cooperative Principle and the Politeness Principle compliment each other and stand next to each other. Fuzzy expressions are commonly regarded as a politeness strategy. Politeness is the most acknowledged motivation of using fuzzy expressions in advertising English. The Politeness Principle may serve as the systematic basis for a pragmatic analysis of fuzziness.

Leech points out that politeness concerns a relationship between two participants whom he calls "self" and "other", and politeness is a strategy of conflict avoidance calculated on the basis of "cost" and "benefit". It helps to explain why people tend to use fuzzy language to show their intentions indirectly. According to Leech, people usually observe the following six maxims in their communication (1966, p.132):

A. Tact Maxim (in impositives and commissives)

(a) Minimize cost to other.

(b) Maximize benefit to other.

B. Generosity Maxim (in impositives and commissives)

(a) Minimize benefit to self.

(b) Maximize cost to self.

C. Approbation Maxim (in expressives and assertives)

(a) Minimize dispraise of other.

(b) Maximize praise of other.

D. Modesty Maxim (in expressive and assertives)

(a) Minimize praise of self.

(b) Maximize dispraise of self.

E. Agreement Maxim (in assertives)

(a) Minimize disagreement between self and other.

(b) Maximize agreement between self and other.

F. Sympathy Maxim (in assertives)

(a) Minimize antipathy between self and other.

(b) Maximize sympathy between self and other.

It is of great importance to the advertiser that he should not impose his opinion on his target audience, for if the audience feels the advertisement to be too rude, he or she is likely to response unhappily to the message, or simply forgets about it very soon. Therefore, the copywriter will face a problem: on the one hand, his advertisement should persuade people to buy the product; on the other hand, he must not show this in so many words so that they should make offence. He has to follow the maxim of Politeness Principle rather than by using more prudent, direct ways of communication. Politeness is a universal communicative rule that works in all kinds of social contacts. Politeness is an essential part of human culture and a crucial criterion of human's social 
communication. As a rule of social activity, people must observe this criterion of social communication. Further more, we find advertisers use fuzzy language in their advertisements in that they observe Politeness Principle.

In Politeness Principle, each maxim is accompanied by a sub-maxim, which is of less importance, and not all the maxims are equally important. For instance, tact influences what we say more powerfully than does generosity while approbation is more important than modesty. Speakers may adhere to more than one maxim of politeness at the same time and often one maxim is on the forefront of the utterance, with a second maxim being invoked by implication. The copywriters' purpose is to influence the consumers and persuade them to buy their products or services, copywriters need to show their concern for consumers' benefits (Tact Maxim) and difficulties (Sympathy Maxim), exaggerate their own loss (Generosity Maxim), praise consumers to attract attention (Approbation Maxim), minimize the praise of self (Modesty Maxim), and achieve agreement with consumers (Agreement Maxim). Fuzzy language may be a good way because they have no definite boundaries and can be understood favorably when appropriately used. For example:

(1) Go the Green and Gold!!Over $\$ 15$ million worth of prizes could be won! (McDonald)

(2) Clearance sale up to $40 \%$ off. (The Sports Authority)

(3) With America's best warranty, we see a very long life in your future. (Hyundai)

(4) Just like you, we care about how your kids feel. (Johnson\&Johnson Skincare)

(5) Just slightly ahead of our times. (Panasonic)

(6) My son is homophobic, but I hope it's just a phase. (an advertisement for Terrence Higgin Trust).

The above examples conform to Politeness Maxims. The first example maximizes benefits of consumers by indicating a possibility of getting "over $\$ 15$ million worth of prizes". Consumers might understand the "over $\$ 15$ million" as a prize they could win immediately. In fact it is the total sum of the many prizes that the company would offer and one prize may not exceed a hundred dollars. But in order to catch readers 'attention, the advertiser puts the number in a prominent position and leaves out an explanation, so that the advertiser makes it a typical example of how the advertiser makes good use of fuzziness to achieve the observation of Tact Maxim.

Generosity Maxim tells advertisers to maximize their cost as what they do in example (2). It seems that the advertiser sacrifices a lot because the claim goes like "up to $40 \%$ off". Actually, the fuzzy expression "up to" is really a deception here because readers may only pay attention to the " $40 \%$ off " and ignore the "up to", which still includes discounts under $40 \%$. It is the case that advertisers put the largest discount in their advertisement to exaggerate their loss. By doing this, advertisers can make consumers believe a large saving on their part and thus attract them to buy their products.

Example (3) is an observation of Approbation Maxim. By saying that "a very long life in your future", the advertiser implies that the consumers who buy the product can have a very long life. Consumers will not be able to resist the temptation and buy Hyundai: they want to live longer. And that can be achieved with Hyundai automobile as the copywriter suggests. Why not buy a Hyundai that can make us live longer?

The fourth example observes Agreement Maxim. It is necessary and reasonable for the advertiser, a manufacturer of baby skincare goods, to get common knowledge and achieve agreement with parents by claiming "Just like you, we care about how your kids feel." Their enthusiastic concern for how babies feel greatly meets parents' care and will naturally realize the final function: buy the products.

The fifth example conforms to Modesty Maxim. Modesty maxim tells advertisers to minimize the praise of self. By saying "just slightly..." the advertiser aims to make consumers assume that this advertiser is so modest, and is not like others who always boast their products. As is common sense, electronic products are connected with hi-technology, and so many companies compete fiercely in this field. Although the advertiser says that "just slightly ahead of...", the following words imply that it is a great invention! Obviously his product is more advanced than the others'. In fact the advertiser still praises himself. Showing sympathy to the consumers in trouble is another important strategy of advertisers.

In example (6) sympathy is shown by admitting "my son is homophobic". If the reader's son is also homophobic, the gap between the advertiser and the reader is bridged. Consumers may have the same feelings and experiences, and advertiser show more understanding and care. But it doesn't end here, a consolation is given along with the sympathy: It's just a phase, which implies that it only lasts a short period and will end soon. Moved by such compassion and comfort, consumers may immediately let his or her son or daughter accept the treatment. So the advertiser's aim is achieved by observing Sympathy Maxim. 


\subsection{Fuzziness and Relevance Theory}

Relevance theory was put forward by Dan Sperber and Deirdre Wilson in Relevance: Communication and Cognition in 1986 and the second edition in 1995. Sperber and Wilson developed relevance theory, maintaining that communication is a process involving ostension and inference and the human communication is governed by the principle of relevance: every act of ostensive communication communicates a presumption of its own optimal relevance. Relevance theory provides us with an ideal tool for analyzing advertising which is geared to the target audience. They claim that the principles governing inferential communication have their source in some basic facts about human cognition that humans typically pay attention to the most relevant phenomena available, construct the most relevant possible representations of these phenomena, and process these representations in a context that maximizes their relevance. Sperber and Wilson argue that all Gricean maxims, including the Cooperative Principle should be a single principle of relevance, which is defined as: "Every act of ostensive communication communicates the presumption of its optimal relevance"(1995, p.158).

According to Relevance Theory, communication is an ostensive-inferential process. Context, the key factor in communication, is not fixed, undergoes a dynamic change. And every act of communication is a process of searching optimal relevance. In the process of advertising communication, the advertisers employ many strategies that function as the ostensive stimuli. On the one hand, catch the consumers' attention. On the other hand, guide the audience to proceed towards optimal relevance. While the audience's task is to acquire optimal relevance through the stimuli and contextual assumptions. So as an advertiser, he does not only make the audience pay processing effort but also guarantee them certain contextual effects. Otherwise the advertisement will fail to arrive at its propagating and promoting goals.

The essence of Relevance Theory --- "Every act of ostensive communication communicates the presumption of its own optimal relevance." shows that communication is not simply a matter of encoding and decoding, but involves inference. Yet inference has only to do with the hearer. From the communicator's side, communication is viewed as an act of making clear one's intention to express something, which is called ostensive act. Thus, "ostensive-inferential" is a complete characterization of communication. In the communicative act of advertising, we first need to pay attention to the production of advertising messages by advertisers, then examine the subsequent readings/understandings that the audience place upon such messages. As communicators, advertisers encode an intended meaning into an advertising message, they must make manifest what they want to express; while the audience are expected to infer/interpret the message in accordance with the intended or preferred meaning. Thus, advertising is a typical ostensive-inferential process. An example is illustrated here:

\section{(7) It is the taste. (an advertisement for Nescafe)}

The meaning of this sentence is infinite. As audience, we could give several intentional meanings under different situations. For instance, we can imagine a situation like that a little girl hurried home after school, and took the biscuit to eat. Her mother asked why not have lunch at school. The daughter responded: "It is the taste." Obviously, the "taste" she implied is bad. That is the reason why she didn't eat at school. But it is the slogan that makes the Nescafe wide-spread all over the world and brings Nestle Company considerable profit. Why can the same sentence make such different effects? Let's employ the concepts of the dynamic context and ostension-inferential communication of Relevance Theory to explain the phenomenon. From the point of view of consumers, we all know this sentence is the slogan of an ad, and all the advertisers are aimed to publicize his product. The advertiser's purpose is to inform the audience the superior quality of his product and then persuade or influence the target audience to purchase the product. On the basis of these assumptions, the audience become aware of the fact that the advertiser is speaking highly of, not criticizing or depreciating his product, and want the audience to share the advantages of the product. With less processing effort, the audience achieve the real contextual effect the advertiser purposed to constrict. The communication processes successfully. That is the contribution of the optimal relevance. Till now this slogan has been as famous as Nescafe all over the world. It has become a classical example in advertising. To fully understand them requires the great processing efforts from the audience.

Relevance theory appears to be an ideal tool to interpret advertising communication between an advertiser and his audience. Moreover, it sheds light on the fact that the advertising is a form of communication and fuzziness is a useful tool to convey a great deal more than is actually said.

\section{Conclusion}

By applying the Politeness Principle and the Relevance theory , the author has found that fuzzy expressions can convey information effectively, make the advertisement brief and aesthetic, and save advertisers' and consumers' face. According to the Relevance theory, communication is a process involving ostension and inference and that 
human communication is governed by the principle of relevance: every act of ostensive communication communicates a presumption of its own optimal relevance. Ostensive-inferential communication also happens in the interpreting of advertising language.

Generally speaking, fuzziness can make communication smooth and effective as precise language can do. On some occasions, we need precise language, while sometimes fuzzy expressions are required. Fuzziness functions irreplaceably and plays a positive role in human communication and advertising English.

The analysis of fuzziness in advertising English is a complex topic in linguistics and cognitive science, for it covers semantics, pragmatics, logic, prototype theory, and so on. Currently, fuzziness is widely used in advertisements. It is generally acknowledged that fuzziness in advertising language either leads to deception or they prompt the effectiveness of advertising communication. We should take a dialectical attitude to fuzziness in advertising English. That is, they perform not only negative functions but also positive ones. Both advertisers and consumers should make mutual efforts to build a true communicative channel. Advertisers should observe the principle of honesty and consumers also should raise their awareness of self-protection. It is the target audience that really need interpret fuzziness. The ultimate decisive power is in our hands.

\section{References}

Channell, J. (1994). Vague Language. Shanghai: Oxford University Press and Shanghai Foreign Language Education Press.

Grice, H. P. (1975). Logic and conversation. In Cole, P. and Morgan, J. (Eds.), Syntax and Semantics J. Speech Acts. New York: Academic Press, pp.41-58.

Lakoff, G. (1972). Hedges: a study in meaning criteria and the logic of fuzzy concepts. Chicago Linguistic Papers. Chicago: Chicago Linguistic Society, pp.183-228.

Leech, G. (1966). English in Advertising: A Linguistic Study of Advertising in Great Britain. London: Longman.

----. (1983) Principles of Pragmatics. London: Longman.

Sperber D., and D. Wilson. (1995). Relevance: Communication and Cognition. Oxford: Blackwell.

Thomas, J. (1995). Meaning in Interaction. London, New York: Longman.

Wu, Shixiong \& Chen, Weizhen. (2001) Retrospect of and Prospect for Fuzzy Linguistics Research in China. Foreign Language Teaching and Research, 7-14. 